\title{
Sperm reduces female longevity and increases melanization of the spermatheca in the bumblebee Bombus terrestris $\mathrm{L}$.
}

\section{Journal Article}

Author(s):

Greeff, Michael (1); Schmid-Hempel, Paul

Publication date:

2008-09

Permanent link:

https://doi.org/10.3929/ethz-b-000014045

Rights / license:

In Copyright - Non-Commercial Use Permitted

Originally published in:

Insectes sociaux 55(3), https://doi.org/10.1007/s00040-008-1007-4 


\title{
Sperm reduces female longevity and increases melanization of the spermatheca in the bumblebee Bombus terrestris $\mathbf{L}$.
}

\author{
M. Greeff and P. Schmid-Hempel* \\ ETH Zurich, Institute of Integrative Biology (IBZ), Experimental Ecology, ETH-Zentrum CHN, CH-8092 Zurich, Switzerland, \\ e-mail:psh@env.ethz.ch
}

Received 30 December 2007; revised 27 April 2008; accepted 1 May 2008.

Published Online First 13 June 2008

\begin{abstract}
Here we present evidence that the male mating products (sperm and gland products) reduce survival during hibernation of queens of the bumblebee $B$. terrestris. Most remarkably, the inseminated queens are significantly more likely to have melanized spermathecae than their virgin sisters. Although we could not detect a direct relationship between these two findings they are quite remarkable since $B$. terrestris is a monandrous and comparably long-lived insect where sexual conflict is unlikely to evolve. The reduced survival can probably be attributed to a general cost of maintaining the sperm, whereas the presence of melanized spermathecae in the inseminated queens may indicate a pathogen transferred during mating or genetic incompatibilities between males and queens.
\end{abstract}

Keywords: Bombus terrestris, bumblebees, melanization, longevity, spermatheca.

\section{Introduction}

In many polyandrous species males and females seriously differ in their reproductive interests, a situation that generates sexual conflict (Parker, 1979). Since males more intensively compete with other males for access to female products than vice versa, males have evolved a number of ways to manipulate females in their own favor (Cordero, 1995; Eberhard, 1996; Baer and SchmidHempel, 2005; Chapman, 2006). For example, during mating special gland products are often transferred in addition to sperm. These products can induce oogenesis

\footnotetext{
* Author for correspondence.
}

and increase oviposition rates (Simmons, 2001), yet reduce the willingness of females to re-mate (Chen et al., 1988; Baer et al., 2001) or may even be toxic to the female (Chapman et al., 1995; Gillott, 1996). Alternatively, in some species, females benefit from products of the seminal fluid. For example, in the bruchid beetle, Bruchidius dorsalis, males transfer a nuptial gift during copulation - compounds in the seminal fluid serve as a source of nutrients for females (Gillott, 1996; Takakura, 2004). Proteins released by the accessory glands and the ejaculatory ducts in males of Drosophila melanogaster were also shown to have antimicrobial and antifungal properties (Samakovlis et al., 1991; Chapman, 2001; Lung et al., 2001).

Among social Hymenoptera, such conflict-generating polyandry is rare (Strassmann, 2001). Therefore, the conflict between the sexes based on sperm competition is not expected to be very pronounced in this group. Moreover, females of social Hymenoptera commonly become inseminated only during one mating episode in their life (Boomsma and Ratnieks, 1996; Strassmann, 2001) and use the sperm which is stored in the spermatheca for up to several decades (Weber, 1972; Keller, 1998). In such a scenario males should not evolve traits that affect the longevity of the females. Here we investigated the effects of the male mating products on the survival of females during hibernation in the annual, eusocial, and monandrous bumblebee Bombus terrestris L. (Hymenoptera; Apoidea) whose reproductive system has received significant attention during the past years (Baer, 2003). Given the arguments outlined above, no adverse male interference with female viability and fecundity should be expected, as the interests of both sexes converge with strict monandry and a single mating episode. However, as mentioned below, male effects on female longevity have been observed. 
In B. terrestris, at the end of the colony cycle, the young queens emerge and mate once with a single male and store the sperm in their spermatheca until they start a new colony after hibernation (Schmid-Hempel and SchmidHempel, 2000). Male bumblebees conduct mate guarding (Duvoisin et al., 1999) and place a mating plug inside the female's sexual tract containing substances that cause a reduction in the propensity of the queens to mate again. In addition, the plug also physically seals off the entrance to the genital tract (Baer et al., 2000, 2001). The plug consists of a cyclic peptide (cycloprolylproline) and four fatty acids (palmitic, linoleic, oleic, and stearic acid), of which linoleic acid is the key compound that triggers the behavioral response. The energetic value of the plug was measured and estimated to allow an average sized queen to remain aloft for 2.3 seconds if she could fully metabolize the plug (Sauter et al., 2001). Therefore, the plug has virtually no nutritional value and is likely to benefit the male to secure his paternity.

In previous experiments, fitness effects on inseminated queens of sperm alone were tested by artificially inseminating queens (Baer and Schmid-Hempel, 2001, 2005; Korner and Schmid-Hempel, 2003). These studies showed that different patrilines had a significant effect on female longevity and on fitness, and that singly inseminated queens survived longer than multiply inseminated queens. At present, it remains largely obscure by what mechanisms sperm influence the females of bumblebees. Besides the possible transmission of diseases while inseminating the queens, genetic incompatibilities (Zeh and Zeh, 2003) or immune reactions after insemination (Baer et al., 2006) offer potential explanations. Furthermore, the extra effects of the accessory gland-products (as compared to sperm alone) on survival and fitness of the queens of $B$. terrestris have not been investigated so far, nor is it fully evident from the conditions of this species what should be expected. It is unclear whether the sperm plus the male mating products enhance or diminish the female survival. Our study therefore attempts to investigate this question and compares the survival and the physiological responses of naturally mated and unmated (i.e. virgin) queens during hibernation.

\section{Methods}

As a source of virgin queens we used second-generation daughter queens from a colony derived from a queen of $B$. terrestris that was wildcaught in the spring of 2003 near Zurich (Neunforn area), Switzerland and allowed to build up colonies in the laboratory under standard conditions $\left(20-25^{\circ} \mathrm{C}, 60-70 \%\right.$ r.H., red light and food ad libitum $)$. The virgin males were taken from six colonies, which were obtained from commercial breeders (BioBest ${ }^{\circledR}$ Biological Systems, B-2260 Westerlo) in order to avoid any possible inbreeding or local adaptation effects. Males and queens were removed from the colonies shortly after eclosion from the pupa and kept with pollen and sugar water ad libitum in brother and sister groups.

Queens appear most willing to mate at around 6 days after emergence (Gretenkord, 1997), while males are most active at $16 \pm 7$ days (Duchateau and Marien, 1995). For practical reasons, we used queens and males in an age range of 5-13 and 6-17 days, respectively. The matings were staged as follows: one individual from a pair of sister virgin queens (daughters from the same mother colony) of the same age was placed individually in a plastic box together with one male. The other queen of the pair was placed in another, paired, box with another male but so that the two (same-aged) males in the two paired boxes were brothers. Otherwise, the assignment of mating partners was randomized. In one box, the male's abdomen was dipped into liquid wax in order to seal his genital organs. This prevented actual mating but not mating behavior and courting activities. The other male (i.e. his brother) was left intact and could mate normally (with the sister of his brother's mate). After the unsealed male had copulated (usually after around 30-40 min), the mating opportunity was terminated and the two brothers were removed. The two queens were then provided with sugar water and pollen ad libitum for 5 days. Then, the queens were weighed for the first time on a balance (Mettler AE 240) to the nearest $\mathrm{mg}$, put individually into cardboard matchboxes and transferred into a climate chamber at approx. $4{ }^{\circ} \mathrm{C}$ for artificial hibernation. Every week, the hibernating queens were weighed and their survival was checked. The weekly interval was chosen as a compromise between detailed coverage and not to disturb the hibernating queens too often. As soon as an individual was detected to have died (i.e. an expected average of 3-4 days after the last check, but not later than seven days), it was stored at $-20^{\circ} \mathrm{C}$ for later dissection and inspection.

For dissections, a queen's abdomen was opened in Ringer's saline, the melanization of the spermatheca was recorded and one of the two ovaries was photographed. In each queen, the diameter of the largest oocyte was quantified with ImageJ (http://rsb.info.nih.gov/ij). The fat content of the abdomen was measured according to the protocol of Ellers (1996). For this purpose, the abdomen was dried at $70^{\circ} \mathrm{C}$ for 4 days and weighed to the nearest mg (Mettler AE 240). Afterwards the abdomen was placed in $2 \mathrm{ml}$ of ether for $48 \mathrm{~h}$ to extract the fat. After rinsing with fresh ether the abdomen was again dried at $70^{\circ} \mathrm{C}$ for another 4 days and weighed again. The difference between the measures indicated the amount of fat in the abdomen. Body size was estimated by the length of the radial cell of one of the forewings (Bertsch, 1984). In total 260 queens from one single colony and 260 males from 6 different colonies (number of males per colony: $38,40,40$, $42,48,52$, respectively) were used.

Data were analyzed with SPSS v. 11 for Macintosh. Longevity of queens, body mass, fat-content and length of ovarioles were analyzed using a repeated measures ANOVA with two-tailed probabilities; insemination (whether queens were mated to a waxed or a fertile male) was used as a within subject factor, the colony of the males was used as a between subject factor and the date of the mating served as a covariate. When body size had a significant effect, the data used in the analysis were divided by the corresponding body sizes. Melanization was analyzed with a binary logistic regression $($ Method $=$ Enter) for of the abovementioned factors. Unless specified, data are given as mean \pm 1 SE.

\section{Results}

The survival of the bumblebee queens during hibernation was influenced by insemination even though the difference was small: queens paired with waxed males, on average, died $152 \pm 2.23 \mathrm{~d}(\mathrm{n}=130)$ after the mating, whereas their inseminated sisters perished after $148 \pm 2.08 \mathrm{~d}(\mathrm{n}=130, \mathrm{p}=0.029$, Table 1$)$. Male origin (i.e. the colony from where it came) had no significant effect on survival. However, the date of mating had a highly significant effect with queens that were mated later dying earlier $(\mathrm{p}<0.001$, Table 1$)$. Queen body size did not correlate with the survival of the queens (linear regression: $\mathrm{F}_{1,258}=0.609, \mathrm{p}=0.436$ ). 
Table 1. General linear model for survival of the queens during hibernation.

\begin{tabular}{lrlll}
\hline Survival & & & & \\
\hline Source $^{\dagger}$ & d.f. & MS & $F$ & $p$ \\
\hline Insemination $^{*} 1$ & $2.27 * 10^{3}$ & 4,89 & 0,029 \\
Insemination*Male colony & 5 & $1.04 * 10^{3}$ & 2,23 & 0,055 \\
Insemination*Date mating & 1 & $1.22 * 10^{3}$ & 2,62 & 0,108 \\
Error & 123 & 464 & & \\
& & & & \\
Intercept & 1 & $1.18^{*} 10^{6}$ & $2.05 * 10^{3}$ & $<0.001$ \\
Male colony & 5 & 730 & 1,26 & 0,285 \\
Date mating & 1 & $15.4 * 10^{3}$ & 26,6 & $<0.001$ \\
Error & 123 & 579 & & \\
\hline
\end{tabular}

${ }^{\dagger}$ Insemination as within subject factor; Male colony as between subject factor; Date mating as covariate

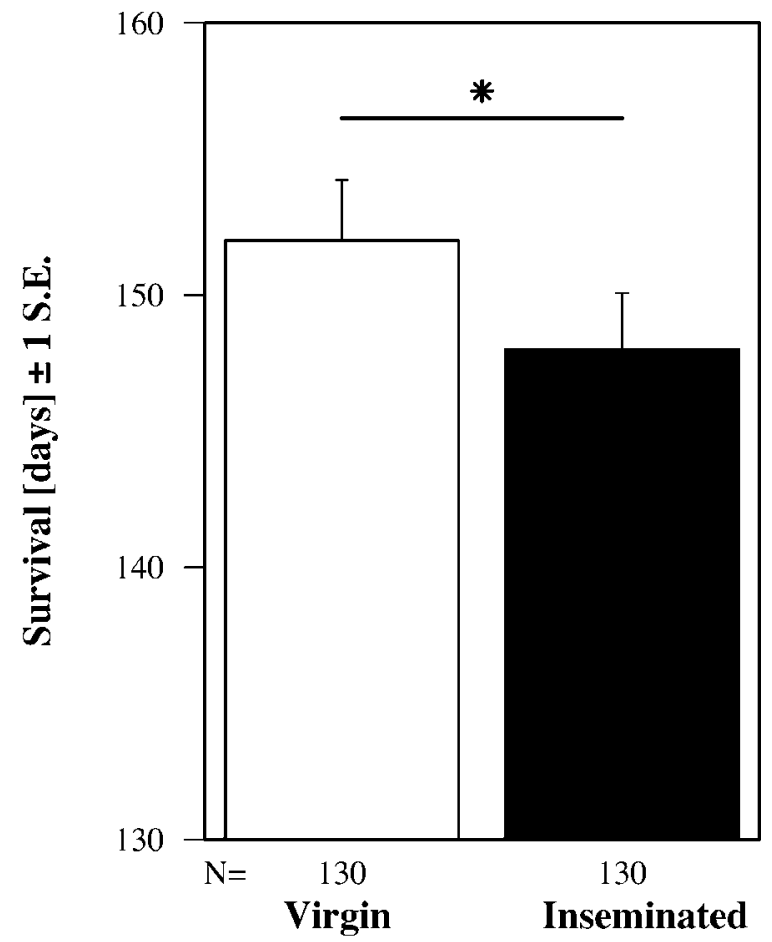

Figure 1. Observed survival of naturally inseminated and virgin bumblebee queens during hibernation in the laboratory. Virgin queens died later than their inseminated sisters $(\mathrm{p}=0.029)$.

Inseminated queens, i.e. those paired with intact males, were significantly more likely to show melanized (i.e. brown or dark) spermathecae compared to their nonmated sisters (non-mated: 2 cases out of total 128 queens, inseminated: 28 out of total 128 queens; binary logistic regression (enter method): $\operatorname{Wald}_{1,256}=15.4, \mathrm{p}<0.001$ ). No effect on melanization was found for male origin $\left(\right.$ Wald $\left._{5,256}=8.551, \mathrm{p}=0.128\right)$, the date of the mating ( Wald $\left._{1,256}=0.002, \quad \mathrm{p}=0.969\right)$ or queen body size $\left(\right.$ Wald $\left._{1,256}=0.174, \mathrm{p}=0.676\right)$. Binary logistic regressions

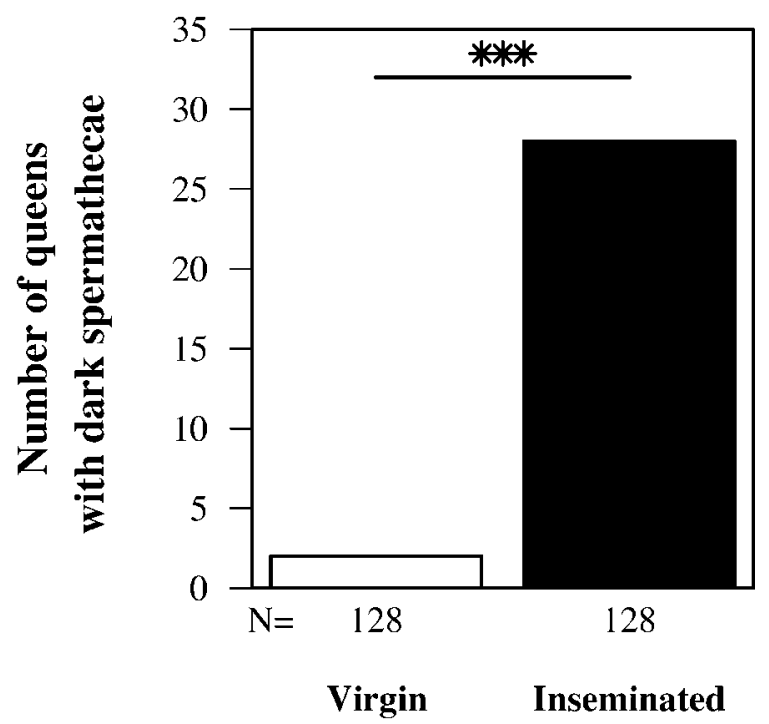

Figure 2. Melanization of the spermatheca in inseminated and virgin bumblebee queens. Dissections were done after the queens had died during hibernation. In 29 out of 128 inseminated queens the spermathecae were melanized whereas virgin queens had only in 2 out of 128 individuals a darkened spermatheca. This difference was significant $(\mathrm{p}<0.001)$.

were done as well either with forward or backward elimination of factors. The results were the same as in the case of the enter method. Effects of the melanization response on the survival of the queens were tested on the data for the inseminated queens alone. No difference between queens with $(145 \pm 3.89 \mathrm{~d}, \mathrm{n}=29)$ and without (average survival $=148 \pm 2.47 \mathrm{~d}, \mathrm{n}=100$ ) melanized spermatheca was detected (t-test: $\left.\mathrm{t}_{127}=0.597, \mathrm{p}=0.552\right)$.

The body masses at the beginning of the hibernation and one week before death both correlated positively with body size (linear regression: before hibernation $\mathrm{F}_{1,258}=169, \mathrm{p}<0.001$; one week before death $\mathrm{F}_{1,258}=135$, $\mathrm{p}<0.001)$; the body mass measures used for the statistical tests (Table 2) were, therefore, related to the corresponding body sizes i.e. taking the ratio. In line with the experimental design, these relative body masses before hibernation were not different between experimental groups (queens paired with waxed males: $187 \pm 1.58 \mathrm{mg}$ / $\mathrm{mm}$, with intact males: $187 \pm 1.56 \mathrm{mg} / \mathrm{mm}$, Table 2) nor did they vary with origin of the males; only the date of the mating had a significant effect with later mating queens being relatively heavier for their body size $(p=0.001$, Table 2).

The same patterns emerged for relative body masses one week before the queens died: no difference between treatment groups (paired with waxed males: $115 \pm 1.07 \mathrm{mg} / \mathrm{mm}$, with intact males: $115 \pm 1.12 \mathrm{mg} /$ $\mathrm{mm}$, Table 2), nor for the origin of the males; yet, the date of the mating had a significant influence (later mating queens being heavier, $\mathrm{p}<0.001$, Table 2).

The fat content of the abdomen of the freshly dead queens correlated positively with their body sizes (linear 
Table 2. General linear model for relative body mass of the queens at the start of hibernation and one week before they died.

\begin{tabular}{|c|c|c|c|c|}
\hline \multicolumn{5}{|c|}{ a) Relative Body Mass at the start of hibernation } \\
\hline Source $^{\dagger}$ & d.f. & MS & $F$ & $p$ \\
\hline Insemination & 1 & 15 & 0,429 & 0,514 \\
\hline Insemination*Male colony & 5 & 32,7 & 0,938 & 0,459 \\
\hline Insemination*Date mating & 1 & 8,09 & 0,232 & 0,631 \\
\hline Error & 122 & 34,9 & & \\
\hline Intercept & 1 & $2.00 * 10^{5}$ & $3.59 * 10^{3}$ & $<0.001$ \\
\hline Male colony & 5 & 47 & 0,844 & 0,521 \\
\hline Date mating & 1 & 607 & 10,9 & 0,001 \\
\hline Error & 122 & 55,7 & & \\
\hline \multicolumn{5}{|c|}{ b) Relative Body Mass before death } \\
\hline Source $^{\dagger}$ & d.f. & MS & $F$ & $p$ \\
\hline Insemination & 1 & 16,7 & 0,958 & 0,33 \\
\hline Insemination*Male colony & 5 & 6,5 & 0,373 & 0,866 \\
\hline Insemination*Date mating & 1 & 19,4 & 1,11 & 0,293 \\
\hline Error & 122 & 17,4 & & \\
\hline Intercept & 1 & $66.7 * 10^{3}$ & $3.38^{*} 10^{3}$ & $<0.001$ \\
\hline Male colony & 5 & 20,1 & 1,02 & 0,408 \\
\hline Date mating & 1 & $1.11 * 10^{3}$ & 56,4 & $<0.001$ \\
\hline Error & 122 & 19,7 & & \\
\hline
\end{tabular}

${ }^{\dagger}$ Insemination as within subject factor; Male colony as between subject factor; Date mating as covariate

regression $\left.\mathrm{F}_{1,257}=22.0, \mathrm{p}<0.001\right)$; the fat measurements analyzed in the repeated ANOVA (Table 3 ) were thus standardized for body size by taking the respective ratio. Neither treatment (paired with waxed males: $4.96 \pm 0.162 \mathrm{mg} / \mathrm{mm}$, with intact males: $5.66 \pm 0.127 \mathrm{mg} /$ $\mathrm{mm}$, Table 3) nor the colony of the males had a significant influence on the fat content; only the date of mating showed an effect (increasing fat content at later dates, $\mathrm{p}=0.001$, Table 3).

Finally, the lengths of the ovarioles correlated positively with body size (linear regression $\mathrm{F}_{1,155}=5.54$, $\mathrm{p}=0.020$ ); measurements were again standardized for body size for the further statistical analysis (Table 4). Because the photographic material did not always allow an accurate measurement, the ovaries could be analyzed only in 156 queens. There was no significant difference in the relative ovariole length of queens paired with waxed males versus their sisters paired with intact males (waxed: $89.3 \pm 1.27 \mu \mathrm{m} / \mathrm{mm}$, intact: $91.5 \pm 1.10 \mu \mathrm{m} / \mathrm{mm})$. The colonies of the males had no significant effect on the lengths of the ovarioles nor did the date of mating (Table 4).
Table 3. General linear model for the relative abdominal fat content.

\begin{tabular}{lrlll}
\hline Fat & & & & \\
\hline Source $^{\dagger}$ & d.f. & MS & $F$ & $p$ \\
\hline Insemination & 1 & $4.85^{*} 10^{-7}$ & 1,38 & 0,242 \\
Insemination*Male colony & 5 & $3.60^{*} 10^{-7}$ & 1,03 & 0,405 \\
Insemination*Date mating & 1 & $4.36^{*} 10^{-8}$ & 0,124 & 0,725 \\
Error & 122 & $3.51^{*} 10^{-7}$ & & \\
& & & & \\
Intercept & 1 & $1.26^{*} 10^{-4}$ & 299 & $<0.001$ \\
Male colony & 5 & $2.15^{*} 10^{-7}$ & 0,51 & 0,768 \\
Date mating & 1 & $5.37^{-6} 10^{-6}$ & 12,7 & 0,001 \\
Error & 122 & $4.22 * 10^{-7}$ & & \\
\hline
\end{tabular}

${ }^{\dagger}$ Insemination as within subject factor; Male colony as between subject factor; Date mating as covariate

\section{Discussion}

We found a slight but still significant negative effect of insemination, that is, exposure and mating with intact males, on the survival of hibernating queens. Although during mating males transfer a variety of peptides in addition to sperm, which change the behavior of the queens and seal off the female genital tract via a mating plug, these effects disappear after a few days (Baer et al., 2001; Sauter et al., 2001). But during hibernation, neither insemination nor any other reproductive activity by the queen occurs. Therefore, our finding is especially interesting as both queens and males obviously benefit from prolonged survival of the hibernating queen, rendering any sexual conflict very unlikely to act during this period.

Baer et al. (2006) discovered a cost of sperm storage in the leaf-cutting ant Atta colombica, which became manifest in a reduced ability to raise an immune response against an artificial implant. Most interestingly, the number of sperm within the spermatheca negatively correlated with the strength of the immune response. Since they could exclude a direct triggering of the immune system by the sperm, these costs must be of metabolic nature. The reduced survival of the inseminated queens in our experiment would be compatible with the hypothesis that sperm storage imposes a cost to the inseminated queen although the mechanisms are still unknown. For example, the pure maintenance of sperm viability could be costly. Schoeters and Billen (2000) reported high glycogen content in the cells lining the reproductive tract of the females of $B$. terrestris and assumed this to serve as an energy source for the sperm. In the honey bee Apis mellifera, Collins et al. (2004) found ten- to twenty-fold transcript increases of antioxidative enzymes in the spermathecae of mated queens when compared to unmated queens. Those antioxidative enzymes are thought to reduce the damage by reactive oxygen species common to many biological processes. Alternatively, the sperm themselves may be genetically 
Table 4. General linear model for the relative length of ovarioles.

\begin{tabular}{lclll}
\hline Ovarioles & & & & \\
\hline Source $^{\dagger}$ & d.f. & MS & $F$ & $p$ \\
\hline Insemination & 1 & $8.01 * 10^{-6}$ & 0,612 & 0,437 \\
Insemination*Male colony & 5 & $2.56^{*} 10^{-5}$ & 1,96 & 0,096 \\
Insemination*Date mating & 1 & $2.11 * 10^{-5}$ & 1,61 & 0,208 \\
Error & 71 & $1.31 * 10^{-5}$ & & \\
& & & & \\
Intercept & 1 & $2.67 * 10^{-2}$ & $1.38 * 10^{3}$ & $<0.001$ \\
Male colony & 5 & $1.20^{*} 10^{-5}$ & 0,621 & 0,684 \\
Date mating & 1 & $1.40 * 10^{-5}$ & 0,723 & 0,398 \\
Error & 71 & $1.93 * 10^{-5}$ & & \\
\hline
\end{tabular}

${ }^{\dagger}$ Insemination as within subject factor; Male colony as between subject factor; Date mating as covariate

incompatible with some parts of the females' physiology or immune system. Such mechanisms have been investigated during the past years (Zeh and Zeh, 2003). In $B$. terrestris, for example, strong paternal effects on survival appeared after artificial insemination where any effect of additional male products could be largely excluded (Korner and Schmid-Hempel, 2003). Activation of the immune system has been shown to reduce the longevity of bumblebee workers under stressful conditions (Moret and Schmid-Hempel, 2000). In our experiment we could not find any paternal effects on the survival of the queens. Although paternal effects are difficult to prove as large sample sizes are required in order to show such interactions, we can fairly exclude the influence of genetic incompatibilities on survival. Likewise, the inseminated queens with melanized spermatheca did not die significantly earlier in our experiment than those with clear spermatheca. Reduced survival of the inseminated queens therefore does not seem to relate to the melanization of the spermathecae. The most parsimonious explanation for the reduced survival of the queens is, therefore, that sperm impose a general cost of maintenance. The reason for the significant effect of the date of mating on the survival of the queens (and as well on other parameters of this experiment) is so far enigmatic.

We found a highly significant rise in the frequency of melanized spermatheca in mated, inseminated bumblebee queens compared to non-mated, virgin queens. Melanization is a key reaction in the immune system of insects (Ashida and Brey, 1995). It is governed by the enzyme phenoloxidase (PO), which is stored as an inactive proenzyme in haemocytes and catalyzes the chemical cascade that leads to the formation of melanin. The reaction intermediates (mainly reactive oxygen species) generated in the enzymatic cascade from tyrosine to melanin are toxic to most microorganisms (Cerenius and Soderhall, 2004) and are under tight control as the insect itself would suffer from a systemic activation. Most interestingly, $\mathrm{PO}$ is also found in the cuticular matrix that lines the reproductive ducts. There, it plays a role in the sequestration of fungal pathogens. Zeh and Zeh (2003) suggest an "immunologically hostile female reproductive tract to provide a physiological screening process capable of weeding out incompatible genotypes in sperm", even though they thought of polyandrous species. In a monandrous social hymenoptera like $B$. terrestris, such a scenario is very unlikely to evolve, since the sperm from a single (haploid) father is clonal and would thus not offer any genotypic variation to be screened. However, once the reproductive tract is immunologically competent it may raise immune responses spuriously. Rather than playing a role in the avoidance of incompatible sperm from a single father, melanization could create a mechanism of incompatibility with regard to different fathers, provided the female has the opportunity to re-mate (which again is rare in $B$. terrestris). In the Drosophila nasuta subgroup, for example, interspecific matings were found to result in melanized and persistent reaction masses in the genital tract, which - given the description - correspond to the mating plugs of the bumblebees. In intraspecific matings the reaction masses remained soft and clear, and disappeared after a while (Asada and Kitagawa, 1988). No such data exist for bumblebees yet. It is unclear whether in our experiment mating incompatibilities were apparent. Mating incompatibilities would manifest themselves as interaction effects (paternal $\mathrm{x}$ maternal lines) and are difficult to prove as they require large sample sizes. In our experiment we could not find such effects.

Finally, it may be that the males transferred a pathogen or other material during mating. In the honeybee $A$. mellifera, Fievet et al. (2006) found virus infections both of the queens' ovaries and the drones' seminal vesicles. In B. terrestris, however, there is no evidence for sexual transmitted diseases so far (Macfarlane et al., 1995). Although no bumblebee used in this experiment showed any unusual signs that could indicate an infection, the possibility of a contagion during mating cannot completely be excluded.

No significant differences could be detected between inseminated and virgin queens in terms of fat content of the abdomen, ovary size or body mass. Fat reserves in $B$. terrestris are usually built up before hibernation independently from insemination (Alford, 1975). The maturation of the ovaries depends largely on the amount of juvenile hormone (Bloch et al., 2000), which is governed by the corpora allata. Previous studies have shown that the corpora allata are small and inactive before hibernation (Palm, 1948). In queens, ecdysteroid titers were higher in colony-heading queens when compared to solitary phase queens (post-mating to end of diapause) (Geva et al., 2005). Palm concluded that only after a successful hibernation the ovaries can start to grow. Since all of our bumblebees died during hibernation no differences in ovary size should be expected between inseminated and virgin queens. 
We therefore conclude that a reduced survival of inseminated queens if compared to their virgin sisters, most likely results from costs of keeping the sperm alive. In addition, the melanization responses in the spermathecae of inseminated queens hint at mating incompatibilities or at transfer of pathogens. Immune response within the genital tract may give valuable insights for the understanding of the invertebrate immune system. Processes of self/non-self discrimination could in conjunction with mating incompatibilities favour the formation of subgroups within a population and eventually, the origin of novel species.

\section{Acknowledgements}

We thank D. Trujillo-Villegas for his help on the dissections of the bees. The Swiss National Science Foundation (grant nr. 3100-066733 to PSH) supported this study.

\section{References}

Alford D.V. 1975. Bumblebees. Davis-Poynter, London. 352 pp

Asada N. and Kitagawa O. 1988. Insemination reaction in the Drosophila nasuta subgroup. Jpn. J. Genet. 63: 137-148

Ashida M. and Brey P.T. 1995. Role of the integument in insect defense - Pro-phenol oxidase cascade in the cuticular matrix. Proc. Natl. Acad. Sci. USA 92: 10698-10702

Baer B. 2003. Bumblebees as model organisms to study male sexual selection in social insects. Behav. Ecol. Sociobiol. 54: 521-533

Baer B., Armitage S.A.O. and Boomsma J.J. 2006. Sperm storage induces an immunity cost in ants. Nature 441: 872-875

Baer B., Maile R., Schmid-Hempel P., Morgan E.D. and Jones G.R. 2000. Chemistry of a mating plug in bumblebees. J. Chem. Ecol. 26: $1869-1875$

Baer B., Morgan E.D. and Schmid-Hempel P. 2001. A nonspecific fatty acid within the bumblebee mating plug prevents females from remating. Proc. Natl. Acad. Sci. USA 98: 3926-3928

Baer B. and Schmid-Hempel P. 2001. Unexpected consequences of polyandry for parasitism and fitness in the bumblebee, Bombus terrestris. Evolution 55: 1639-1643

Baer B. and Schmid-Hempel P. 2005. Sperm influences female hibernation success, survival and fitness in the bumble-bee Bombus terrestris. Proc. R. Soc. Lond. B Biol. Sci. 272: 319-323

Bertsch A. 1984. Foraging in male bumblebees (Bombus lucorum L). Maximizing energy or minimizing water load. Oecologia 62: 325336

Bloch G., Borst D.W., Huang Z., Robinson G.E., Cnaani J. and Hefetz A. 2000. Juvenile hormone titers, juvenile hormone biosynthesis, ovarian development and social environment in Bombus terrestris. J. Insect Physiol. 46: 47-57

Boomsma J.J. and Ratnieks F.L.W. 1996. Paternity in eusocial Hymenoptera. Phil. Trans. R. Soc. Lond. B Biol. Sci. 351: 947-975

Chapman T. 2001. Seminal fluid-mediated fitness traits in Drosophila. Heredity 87: $511-521$

Chapman T. 2006. Evolutionary conflicts of interest between males and females. Curr. Biol. 16: R744-R754

Chapman T., Liddle L.F., Kalb J.M., Wolfner M.F. and Partridge L. 1995. Cost of mating in Drosophila melanogaster females is mediated by male accessory-gland products. Nature 373: $241-$ 244

Chen P.S., Stummzollinger E., Aigaki T., Balmer J., Bienz M. and Bohlen P. 1988. A male accessory-gland peptide that regulates reproductive-behavior of female Drosophila melanogaster. Cell 54: $291-298$
Cerenius L. and Soderhall K. 2004. The prophenoloxidase-activating system in invertebrates. Immunol. Rev. 198: 116-126

Collins A.M., Williams V. and Evans J.D. 2004. Sperm storage and antioxidative enzyme expression in the honey bee, Apis mellifera. Insect Mol. Biol. 13: 141-146

Cordero C. 1995. Ejaculate substances that affect female insect reproductive physiology and behavior - Honest or arbitrary traits. J. Theor. Biol. 174: 453-461

Duchateau M.J. and Marien J. 1995. Sexual biology of haploid and diploid males in the bumble bee Bombus terrestris. Insect. Soc. 42: 255-266

Duvoisin N., Baer B. and Schmid-Hempel P. 1999. Sperm transfer and male competition in a bumblebee. Anim. Behav. 58: 743-749

Eberhard W.G. 1996. Female Control: Sexual Selection by Cryptic Female Choice. Monographs in Behaviour and Ecology. Princeton University Press. $472 \mathrm{pp}$

Ellers J. 1996. Fat and eggs: An alternative method to measure the trade-off between survival and reproduction in insect parasitoids. Neth. J. Zool. 46: 227-235

Fievet J., Tentcheva D., Gauthier L., de Miranda J.R., Cousserans F., Colin M.E. and Bergoin M. 2006. Localization of deformed wing virus infection in queen and drone Apis mellifera L. Virol. J. 3:1-5

Free J.B. and Butler C.G. 1959. Bumblebees. Collins, London. 208 pp

Geva S., Hartfelden K. and Bloch G. 2005. Reproductive division of labor, dominance, and ecdysteriod levels in hemolymph and ovary of the bumble bee Bombus terrestris. J. Insect Physiol. 51: $811-823$

Gillott C. 1996. Male insect accessory glands: Functions and control of secretory activity. Invertebr. Reprod. Dev. 30: 199-205

Gretenkord C. 1997. Laborzucht der Dunklen Erdhummel (Bombus terrestris L.) (Hymenoptera, Apidae) und toxikologische Untersuchungen unter Labor- und Halbfreilandbedingungen. Ph.D. thesis, University of Bonn

Keller L. 1998. Queen lifespan and colony characteristics in ants and termites. Insect. Soc. 45: 235-246

Korner P. and Schmid-Hempel P. 2003. Effects of sperm on female longevity in the bumble-bee Bombus terrestris L.. Proc. R. Soc. Lond. B Biol. Sci. 270: S227-S229

Lung O., Kuo L. and Wolfner M.F. 2001. Drosophila males transfer antibacterial proteins from their accessory gland and ejaculatory duct to their mates. J. Insect Physiol. 47: 617-622

Macfarlane R.P., Lipa J.J. and Liu H.J. 1995. Bumble bee pathogens and internal enemies. Bee World 76: $130-148$

Milliron H.E. 1967. A successful method for artificially hibernating Megabombus $F$ fervidus and notes on a related species (Hymenoptera - Apidae Bombinae). Can. Entomol. 99: 1321-1332

Moret Y. and Schmid-Hempel P. 2000. Survival for immunity: The price of immune system activation for bumblebee workers. Science 290: $1166-1168$

Palm N.B. 1948. Normal and pathological histology of the ovaries in Bombus Latr. (Hymenopt.). Op. Entomol. Suppl. 7: 1-101

Parker G.A. 1979. Sexual Selection and Sexual Conflict. In: Blum M.S and Blum N.A. (eds.). Sexual Selection and Reproductive Competition in Insects. Academic Press, New York. 123-166

Samakovlis C., Kylsten P., Kimbrell D.A., Engstrom A. and Hultmark D. 1991. The andropin gene and its product, a male-specific antibacterial peptide in Drosophila-melanogaster. EMBO J. 10: $163-169$

Sauter A., Brown M.J.F., Baer B. and Schmid-Hempel P. 2001. Males of social insects can prevent queens from multiple mating. Proc. $R$. Soc. Lond. B Biol. Sci. 268: 1449-1454

Schmid-Hempel R. and Schmid-Hempel P. 2000. Female mating frequencies in Bombus spp. from Central Europe. Insect. Soc. 47: $36-41$

Schoeters E. and Billen J. 2000. The importance of the spermathecal duct in bumblebees. J. Insect Physiol. 46: 1303-1312

Simmons L.W. 2001. Sperm Competition and its Evolutionary Consequences in the Insects. Monographs in Behaviour and Ecology. Princeton University Press, Oxford. 448 pp

Strassmann J. 2001. The rarity of multiple mating by females in the social Hymenoptera. Insect. Soc. 48: 1-13 
Takakura K. 2004. The nutritional contribution of males affects the feeding behavior and spatial distribution of females in a bruchid beetle, Bruchidius dorsalis. J. Ethol. 22: 37-42

Weber N.A. 1972. Gardening Ants: the Attines. American Philosophical Society, Philadelphia. $146 \mathrm{pp}$
Zeh J.A. and Zeh D.W. 2003. Toward a new sexual selection paradigm: Polyandry, conflict and incompatibility (invited article). Ethology 109: $929-950$

To access this journal online: http://www.birkhauser.ch/IS 